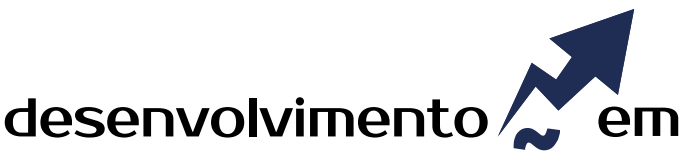 QUESTÃO
}

\section{Percepção de Nutricionistas sobre Aquisição de Produtos da Agricultura Familiar para a Alimentação Escolar no Território de Cidadania Noroeste Colonial - RS}

http://dx.doi.org/10.21527/2237-6453.2020.54.250-261

Recebido em: 31/3/2020

Aceito em: 28/10/2020

\author{
Charlise dos Santos Viccari ${ }^{1}$, Elaine Marisa Andriolli ${ }^{2}$, Marilene Cassel Bueno ${ }^{3}$, \\ Antonio Joreci Flores ${ }^{1}$, Vanessa Ramos Kirsten ${ }^{1}$
}

\begin{abstract}
RESUMO
A Lei no 11.947/2009 garante a alimentação escolar para os alunos de toda educação básica pública e exige que, do total dos recursos repassados pelo Fundo Nacional de Desenvolvimento da Educação para os municípios ou Estados, pelo menos $30 \%$ sejam utilizados para a aquisição de produtos oriundos da agricultura familiar. O objetivo desta pesquisa foi analisar a percepção dos nutricionistas ante as dificuldades encontradas para a compra de alimentos dos agricultores familiares e os benefícios que essa Lei trouxe para cada município do Território Noroeste Colonial - RS. Estudo descritivo de caráter qualitativo, para o qual foram entrevistados os nutricionistas dos três municípios com maior e com menor percentual de compra da agricultura familiar no ano de 2014. As entrevistas foram realizadas no período de maio a setembro de 2016, individualmente no ambiente de trabalho destes profissionais, as quais foram gravadas e, posteriormente, transcritas e analisadas. Todos os entrevistados afirmaram que o Programa Nacional de Alimentação Escolar fortalece a agricultura familiar local, além de gerar mais emprego e renda para o município, e destacam que, com o Programa, os alunos recebem uma alimentação de melhor qualidade e mais saudável. Dentre as principais dificuldades encontra-se a falta de organização por parte dos produtores e questões burocráticas. Na percepção das nutricionistas entrevistadas, portanto, esta Lei beneficiou alunos e agricultores da região, e as principais dificuldades encontradas foram os processos burocráticos, organização da produção e inspeção sanitária.
\end{abstract}

Palavras-chave: Alimentação escolar. Nutricionista. Desenvolvimento rural. Políticas públicas.

\section{PERCEPTION OF NUTRICIONISTS ABOUT THE ACQUISITION OF FAMILY AGRICULTURE PRODUCTS FOR SCHOOL FOOD IN THE COLONIAL NORTHWEST CITIZENSHIP TERRITORY - RS}

\begin{abstract}
Law no 11.947/2009 guarantees School Meals for students in all public basic education and requires that of the total resources transferred by the National Education Fund Education Development for municipalities or states, at least $30 \%$ are used to purchase products from family farming. The objective of this research was to analyze the perception of nutritionists in view of the difficulties encountered in the purchase of food from family farmers and the benefits that this Law brought to each municipality of the Northwest Territory Colonia - RS. Qualitative descriptive study, where nutritionists from the three municipalities with the highest and lowest percentage of family farming purchases were interviewed in 2014. The interviews were conducted from May to September 2016, individually in the work environment of these professionals, which were recorded, later transcribed and analyzed. All respondents stated that the National School Feeding Program strengthens local Family Farming, in addition to generating more jobs and income for the municipality, highlight that with the Program students receive better quality and healthier food. Among the main difficulties is the lack of organization on the part of producers and bureaucratic issues. Therefore, in the perception of the interviewed nutritionists, this Law benefited students and farmers in the region and the main difficulties encountered were bureaucratic processes, organization of production and health inspection.
\end{abstract}

Keywords: School feeding. Nutritionist. Rural development. Public policy.

\footnotetext{
${ }^{1}$ Universidade Federal de Santa Maria (UFSM). Santa Maria/RS, Brasil.

${ }^{2}$ Prefeitura de Novo Barreiro/RS, Brasil.

${ }^{3}$ Autora correspondente. Universidade Federal do Rio Grande do Sul (UFRGS). Av. Paulo Gama, 110 - Bairro Farroupilha. CEP 90040-060. Porto Alegre/RS, Brasil. http://lattes.cnpq.br/6630546051364984. http://orcid.org/0000-0001-9229-519X. marilenecassel@outlook.com
} 
A agricultura familiar é apontada como responsável por uma boa parte do abastecimento alimentar no Brasil, porém há muito pouco tempo ela começou a ser reconhecida pelas políticas públicas como um segmento que merecesse apoio (GRISA; SCHNEIDER, 2014; TURPIN, 2009). Os alimentos produzidos por agricultores familiares faziam parte da alimentação servida nas escolas por meio do Programa de Aquisição de Alimentos (PAA), que iniciou em 2003, ainda antes da obrigatoriedade trazida com a Lei no 11.947/2009 referente à alimentação escolar, servindo como uma etapa preparatória para a execução de um novo modelo de compras exigido pelo Programa Nacional de Alimentação Escolar (PNAE) em 2009 (BRASIL, 2012). Em 2003 o governo federal resolveu adotar o enfoque territorial para a instituição de políticas com o objetivo de aprofundar o caráter participativo e decisório dos agricultores familiares em sua aplicação, gestão e monitoramento. Essa estratégia foi ampliada e rebatizada, em 2009, como Programa Territórios da Cidadania (PTC) (CANIELLO, 2016).

Localizado no Noroeste do Rio Grande do Sul, o Território de Cidadania Noroeste Colonial foi criado como parte do Programa Territórios da Cidadania do governo federal, que tinha por objetivos promover o desenvolvimento econômico e universalizar programas básicos de cidadania por meio de uma estratégia de desenvolvimento territorial sustentável (BRASIL, 2013). A Universidade Federal de Santa Maria, com o seu campus localizado na cidade de Palmeira das Missões, foi contemplada com um edital do Conselho Nacional de Desenvolvimento Científico e Tecnológico ${ }^{4}$, no ano de 2014, para fomentar um núcleo de ações de extensão em Desenvolvimento Territorial neste território. Teve como objetivos a identificação e a produção de dados, informações e conhecimentos, bem como a difusão de métodos e tecnologias sociais como instrumentos de monitoramento, avaliação e assessoria ao colegiado do Território da Cidadania do Noroeste Colonial no acompanhamento das ações de desenvolvimento territorial do Ministério do Desenvolvimento Agrário.

Alexandre et al. (2016) explicam que, por existirem poucos estudos na literatura avaliando os benefícios e as dificuldades trazidas pela Lei № 11.947/2009 do PNAE em Territórios de Cidadania, optou-se por avaliar esses aspectos no Território de Cidadania Noroeste Colonial-RS, uma área com 34 municípios na qual a agricultura familiar está bastante presente, o que pode favorecer o desenvolvimento local por meio da produção de alimentos e sua posterior venda (BRASIL, 2011).

Em 16 de junho de 2009 foi aprovada a Lei no 11.947, que dispõe, em seu artigo 14 , a obrigatoriedade de que pelo menos $30 \%$ dos recursos repassados pelo Fundo Nacional de Desenvolvimento da Educação (FNDE) para os Estados ou municípios para a alimentação escolar, sejam utilizados para a aquisição de produtos oriundos da agricultura familiar, valorizando o pequeno empreendedor rural (BRASIL, 2009b). Esta Lei foi aprovada visando a uma melhora na sua estrutura e organização, dispondo sobre o atendimento da Alimentação Escolar e tratando de aspectos relacionados à qualidade da alimentação disponibilizada para os alunos, além de trabalhos de educação alimentar com eles (BACCARIN et al., 2011).

${ }^{4}$ Aprovado na Chamada CNPq/MDA/SPM-PR no 11/2014 e que foi encerrado em abril de 2017. 
Estudos demonstram que o PNAE tem produzido bons resultados, principalmente no que diz respeito à reeducação alimentar dos escolares, além de uma valorização maior dos alimentos locais e culturais (BELIK; CHAIM, 2009), posto que esses alimentos devem ser priorizados no momento em que o cardápio é elaborado pelos nutricionistas (BRASIL, 2006).

Com isso, a necessidade de ter um nutricionista responsável técnico passou a ser obrigatório e de extrema importância na execução do PNAE, uma vez que é ele que deverá planejar e elaborar cardápios respeitando a cultura alimentar dos alunos e a disponibilidade agrícola da região, podendo ser considerado um dos atores principais na gestão e execução da Lei do PNAE (BRASIL, 2009b). Destaca-se, também, que no ano de 2010 o Conselho Federal de Nutricionistas publicou a Resolução no 465, que orienta a atuação do profissional no Programa e, entre outras funções, cabe a ele elaborar cardápios com a utilização dos produtos da Agricultura Familiar, interagir com os agricultores a fim de conhecer a produção local e participar do processo de licitação e da compra direta da agricultura familiar (BRASIL, 2010). Desse modo, os profissionais têm uma responsabilidade importante na articulação com o cardápio elaborado e o contato com os agricultores e cooperativas, atuando ativamente na execução do PNAE.

Diante disso, considerando que existem poucos estudos realizados em Territórios com características agrícolas importantes e a necessária atuação dos nutricionistas na execução do programa, o objetivo deste trabalho foi analisar a percepção dos nutricionistas sobre a aquisição de alimentos da agricultura familiar para a Alimentação Escolar no Território de Cidadania Noroeste Colonial - RS.

\section{MÉTODOS}

Este estudo de abordagem qualitativa foi realizado com nutricionistas com Responsabilidade Técnica (RT) atuantes no PNAE em municípios pertencentes ao Território de Cidadania Noroeste Colonial - RS, conforme ilustra a Figura 1.

Figura 1 - Mapa do Território de Cidadania Noroeste Colonial
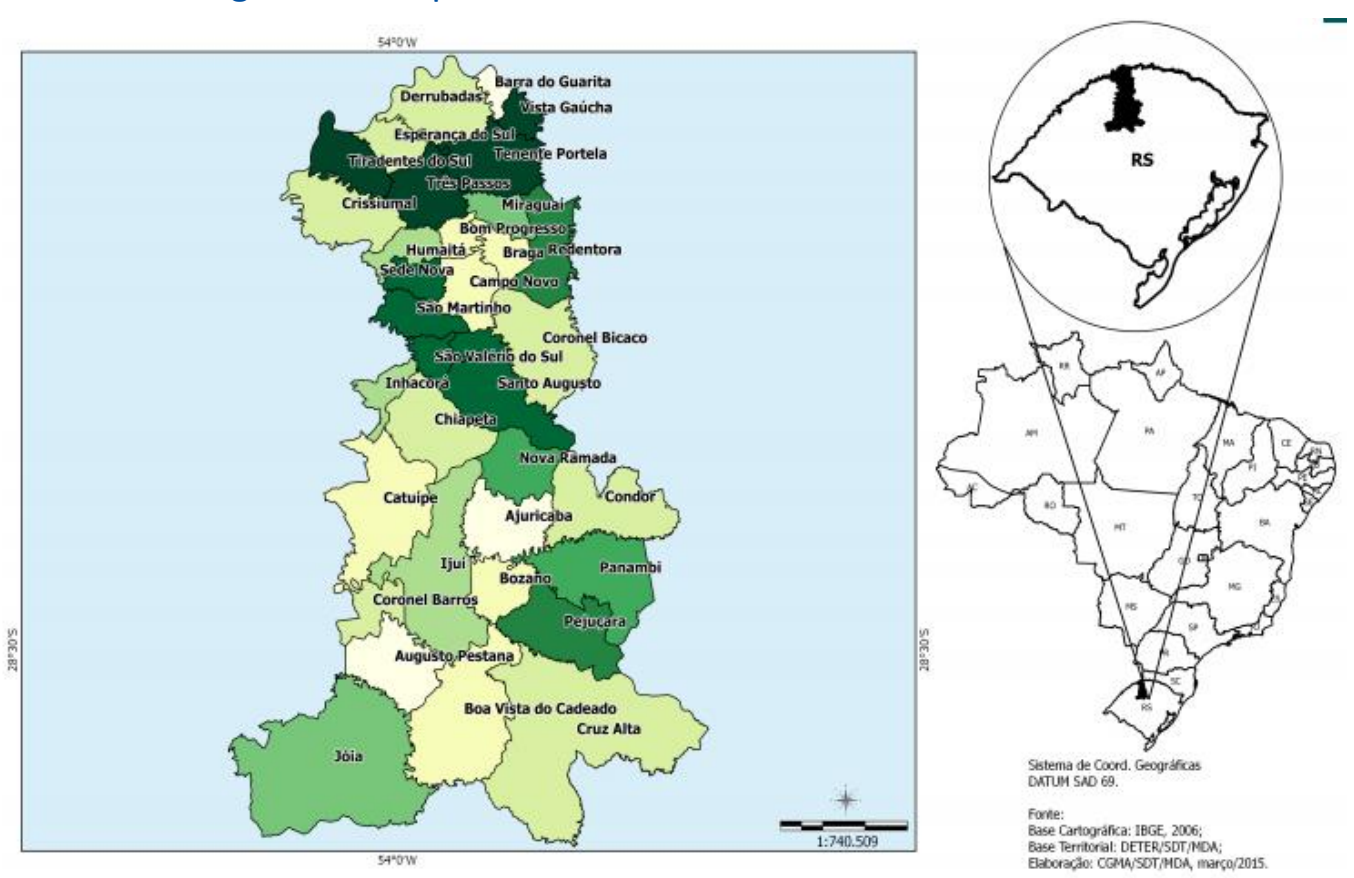

Fonte: SIT (2015). 
Para a realização da pesquisa foram incluídos três municípios que mais adquiriram e três que menos adquiriram produtos da agricultura familiar para a Alimentação Escolar no ano de 2014, de acordo com as informações disponíveis no website do FNDE (2017). Para ser incluído, o município deveria ter nutricionista atuando exclusivamente na Alimentação Escolar do município. Os critérios de exclusão foram os municípios que não tinham nutricionista, aqueles que não concordaram em participar da pesquisa por meio da assinatura de um Termo de Consentimento Livre e Esclarecido (TCLE) e aqueles que não adquiriram nenhum produto da agricultura familiar. Quando determinado município não participou por recusa ou por não ter nutricionista, seguiu-se uma ordem decrescente do percentual de compra para selecionar o município seguinte.

A coleta de dados ocorreu no período de maio a setembro de 2016, por meio de entrevistas semiestruturadas com os nutricionistas de cada município mediante agendamentos prévios e, após, assinatura do TCLE, com exceção de uma cidade, a qual foi realizada via ligação telefônica. As perguntas foram do tipo sondagem de opinião, em que o entrevistado buscou dar respostas ao entrevistador (BARDIN, 2011; MINAYO, 2010). As questões foram elaboradas com base nos objetivos do estudo e distribuídas de acordo com os seguintes blocos: a) identificação do entrevistado; b) opinião do nutricionista em relação ao Artigo 14을 referente à aquisição de produtos da agricultura familiar para o PNAE da Lei no 11.947/2009; c) principais beneficiados com a Lei no município; d) se houve treinamentos para atuação na compra de produtos da agricultura familiar; e e) dificuldades da execução da Lei no município.

As entrevistas foram realizadas individualmente no ambiente de trabalho desses profissionais, com auxílio de um gravador da marca LG - L70 Dual D325 -, e, posteriormente, foram ouvidas e transcritas em sua totalidade. Os entrevistados são mencionados, no decorrer da pesquisa, de acordo com o número de participantes; por exemplo: N1, N2, N3, N4, N5 e N6 ( $N$ significa Nutricionista), visando o anonimato dos mesmos. Para a análise de dados utilizou-se a técnica de análise de conteúdo com categorias, com as seguintes fases: Pré-análise, Exploração do material e Interpretação dos depoimentos, segundo o descrito por Minayo (2010) e Bardin (2011).

Na Pré-análise realizou-se uma "leitura flutuante" das informações coletadas, considerando todos os aspectos levantados em cada pergunta, organizando as informações coletadas quanto à: validade qualitativa, representatividade e homogeneidade. Na segunda fase - Exploração do material -, o objetivo foi identificar o núcleo de compreensão do texto para alcançar as categorias temáticas. Por fim, na Interpretação dos depoimentos realizou-se a distribuição das categorias temáticas identificadas, com sua interpretação e discussão de acordo com a literatura (MINAYO, 2010; BARDIN, 2011).

Este projeto foi submetido e aprovado pelo Comitê de Ética em Pesquisa da Universidade Federal de Santa Maria (CAAE: 62210316.3.0000.5346) e seguiu os preceitos éticos que regem a pesquisa com seres humanos de acordo com a Resolução № 466/2012 do Conselho Nacional de Saúde.

\section{RESULTADOS E DISCUSSÃO}

Participaram do estudo seis municípios, dos quais os três que mais adquiriram produtos da agricultura familiar para a alimentação escolar no ano de 2014 foram: Tenente Portela (98\%), Derrubadas (81\%) e Panambi (77\%); e os três que menos adquiri- 
ram foram: Barra do Guarita (22\%), Braga (10\%) e Cruz Alta (5\%). Até o momento da coleta de dados não havia divulgação dos valores de 2015 e 2016 referentes ao percentual de compra da agricultura familiar. Dessa forma, foram utilizados os dados de 2014 por serem os últimos divulgados.

Em todos os municípios visitados os questionários foram respondidos pelas nutricionistas que atuavam como responsáveis técnicas do PNAE. Todas eram do sexo feminino, com tempo de atuação na ocupação atual variando de 3 meses à 17 anos. De acordo com Balestrin (2014), este profissional pode ser considerado um importante articulador nos processos de compra dos gêneros alimentícios para o PNAE, auxiliando e organizando as chamadas públicas, desde o contato com os agricultores até a escolha dos produtos. Este aspecto é positivo, posto que o nutricionista também tem um papel importante no processo de educação alimentar, atuando de forma multidisciplinar, mostrando e esclarecendo a real importância do PNAE para os alunos e para a sociedade como um todo (SANTANA; MORENO, 2012).

Em relação à compra de alimentos, de maneira geral os produtos que mais foram adquiridos da agricultura familiar, de acordo com as nutricionistas, foram alimentos in natura (frutas, hortaliças, vegetais). Resultados semelhantes foram encontrados em outros estudos, em que os alimentos na forma in natura predominaram nas chamadas públicas (BACCARIN et al., 2011; FERIGOLLO et al., 2017). Esse fato é positivo pelo alto valor nutricional desses alimentos, que são de consumo recomendado pelo Guia Alimentar para a População Brasileira (BRASIL, 2014).

Ao analisar a Lei no 11.947/2009 e, em especial, o artigo 14, bem como os pontos positivos e os desafios que ela traz para o município, foi observado que há entendimento, por parte das nutricionistas, que a Lei favorece a geração de emprego e renda, além de fortalecer e incentivar os agricultores familiares. As entrevistadas também afirmaram que o PNAE favorece a alimentação mais saudável, contribuindo para a melhoria dos hábitos alimentares e do desempenho escolar, como evidenciam os trechos das entrevistas a seguir:

[...] No caso, essa lei faz com que a gente dê continuidade a esse trabalho, a gente consegue que valorizem o agricultor, comprem do município através da lei (N1).

Eu acho que é um estímulo, tanto para o agricultor quanto para o fornecimento de uma alimentação mais saudável, porque muitas vezes a gente vai comprar no mercado, nem sempre tem tudo disponível, principalmente para nós aqui, que é considerado difícil acesso. Bem difícil da gente conseguir coisas diferentes. Então com a agricultura familiar a gente consegue oferecer a questão dos hortifrútis (N2).

Eu acho que foi uma das políticas mais bem elaboradas né, que vem beneficiar os agricultores familiares que de repente não estavam muito organizados no interior, passando por dificuldades, então eu acho que uma política que veio para beneficiar essas famílias do interior, e colaborar muito na questão da alimentação mais saudável, de qualidade, porque a gente sabe que a nossa alimentação está cada vez mais "artificial", tá deixando de ser aquela alimentação básica (N3).

É uma forma de incentivar o agricultor lá no campo. E alimentos mais saudáveis né (N5).

A valorização da agricultura local e o fornecimento de alimentos mais saudáveis também foram destacados no estudo de Germano, Bueno e Kirsten (2020), que analisou a percepção de nutricionistas que atuam no PNAE em municípios localizados no 
litoral do Rio Grande do Sul. É importante salientar que pela aquisição desses produtos ser local ou regional, o alimento chega mais fresco até as escolas, condição que contribui para a maior qualidade das refeições ofertadas. Nesse sentido, Ferigollo et al. (2017), em estudo que avaliou as chamadas públicas de 52 municípios do RS, apontam que essa Lei contribui para garantir produtos de melhor qualidade, sejam eles in natura ou minimamente processados, uma vez que se conhece a procedência do alimento por ser produzido por agricultores locais, possibilitando fácil acesso e uma entrega rápida do produto, sem necessidade de que os alimentos fiquem estocados durante dias.

De acordo com a percepção das nutricionistas entrevistadas, a compra da agricultura familiar vem contribuindo para a manutenção dos agricultores no campo e, também, para que os jovens permaneçam na agricultura:

Uma coisa que a gente tem observado, no nosso caso aqui, é que o que acontecia é que como a nossa cidade tem bastante indústria quem ficava na agricultura eram os pais. Os filhos fazem 18 anos, vinham para as empresas trabalhar. E hoje a gente já tá vendo esse caminho inverso assim, em alguns casos. Hoje a maioria dos nossos agricultores são jovens, então é uma coisa muito boa (N3).

[...] muitos dos filhos dos agricultores iam embora e com [PNAE] isso você vê eles ficarem mais (N4).

Turpin (2009) destaca a garantia de renda por meio da venda dos alimentos a preços justos e a formalização dos agricultores, como fatores que favorecem a permanência no meio rural. Desse modo, constata-se que, além da potencialidade para estimular o desenvolvimento econômico, o PNAE também favorece o desenvolvimento social, a inclusão de agricultores, a equidade e a valorização de aspectos tradicionais, como destacam Grisa e Schneider (2014).

Avançando em aspectos relacionados aos benefícios da aquisição de produtos da agricultura familiar, há também a percepção de que os alunos são beneficiados, como pode ser observado nos trechos a seguir:

Os alunos né, você tem uma qualidade da merenda melhor, porque você tá pegando direto do agricultor, você consegue conversar com a pessoa, tu sabe que o produto é mais novo (...) (N1).

(...) principalmente na questão de saúde a criança, por ser uma alimentação mais natural, mais saudável. A gente sempre conversa com os agricultores para usarem o mínimo de agrotóxicos e tal, e depois enfim o agricultor também que é beneficiado financeiramente (N3).

Eu acho que as crianças e diretamente os agricultores. É uma cadeia né, e indiretamente acho que todo o município né, aumenta a arrecadação, eles gastam no município (...) (N4).

Para Turpin (2009), a aquisição de alimentos da agricultura familiar contribui para a melhora na qualidade dos alimentos ofertados na alimentação escolar e, consequentemente, nos hábitos alimentares dos escolares. Estes dados são semelhantes ao presente estudo, em que as nutricionistas indicam que tanto os agricultores quanto os alunos são os maiores beneficiados, mostrando que, de fato, a Lei tem surtido efeitos 
positivos que têm evoluído muito ao longo dos anos, pois os agricultores estão cada vez mais engajados e interessados em produzir alimentos em maior quantidade e melhor qualidade.

Outros autores enfatizam a importância de um engajamento maior entre os diversos setores do Poder Executivo, trabalhando em conjunto para potencializar o desenvolvimento local por meio de apoio aos agricultores, como forma de auxílio para aumento de produção (ALEXANDRE et al., 2016; SARAIVA et al., 2013; TRICHES; SCHNEIDER, $2010 b)$. De fato, o apoio aos agricultores faz toda a diferença, pois no presente estudo foi possível observar que aqueles que obtinham recursos, tais como auxílio da Secretaria da Agricultura, participação em cooperativas ou organização de grupos de agricultores e assistência técnica da Emater, obtiveram maior sucesso na produção e posterior venda. Os municípios que prestam apoio aos agricultores familiares e que os setores trabalham em conjunto, são os que adquirem maior quantidade de produtos oriundos da agricultura familiar.

Uma das melhores formas de aperfeiçoar o processo de compras, trabalho interdisciplinar e ter uma visão ampliada da gestão, é por meio das capacitações que são promovidas para os nutricionistas. Nesse contexto, destaca-se o Centro Colaborador em Alimentação e Nutrição do Escolar (Cecane) da Universidade Federal do Rio Grande do Sul (UFRGS), conforme indicado nos trechos das entrevistas a seguir:

A gente teve reunião do Cecane e a gente tem um grupo muito legal aqui junto com o grupo da Amuncelero ${ }^{5}$, a cada dois, três meses que elas têm reunião, nós nutricionistas dos 21 municípios, nos reunimos [...] (N1).

Eu comecei a ter os treinamentos do Cecane, que eu fui em todos, mas da agricultura familiar foram dois. Eu acho que poderia ter mais porque a gente sempre tem bastante dúvidas, principalmente na hora da chamada pública (N2).

A Emater sempre foi, desde o início, uma parceria muito forte, então a gente vai aprendendo, às vezes tem encontro com o Cecane né [...] A gente pegou a lei no início, estudamos, fizemos muitas reuniões [...] (N3).

Pelo Cecane né, a gente teve treinamento, eles vieram aqui. Como eu encontrei dificuldades, eles vieram em 2014 prestar assessoria, vieram três vezes. Fizeram orientação, depois vieram duas vezes fazer a visita (N5).

Pode ser evidenciada, por meio das falas das nutricionistas, a importância dos encontros promovidos pelo Cecane, que, além de proporcionar espaços de conhecimento e orientações em relação às dúvidas em torno da execução do PNAE, torna possível a troca de experiências entre profissionais de diferentes localidades/municípios. Cabe destacar que, no ano de 2006, o FNDE iniciou uma parceria com as instituições federais de ensino, a qual originou a criação dos Cecanes, com a finalidade de oferecer assessoria técnico-científica aos Estados e municípios para a correta execução do PNAE (PEIXI$\mathrm{NHO}, 2013)$.

As capacitações desenvolvidas pelo Cecane/UFRGS são realizadas desde 2010, quando uma equipe presta apoio técnico aos municípios visando à introdução da alimentação saudável, por meio do acompanhamento da execução do PNAE. Atua tam-

${ }^{5}$ Associação dos Municípios da Região Celeiro. 
bém realizando pesquisas na área de saúde e Alimentação Escolar, proporcionando capacitação com nutricionistas, manipuladores de alimentos, conselheiros de Alimentação Escolar, bem como com agricultores (SCARPARO et al., 2010). Desse modo, evidencia-se a importância da atuação cada vez mais ampliada do Cecane no Estado, proporcionando espaços para capacitações e treinamentos no âmbito do PNAE.

Scarparo et al. (2013) verificaram, em seu estudo, a efetividade das formações de nutricionistas realizadas pelo Cecane/UFRGS em municípios do Rio Grande do Sul, no qual observaram efeitos positivos; as participantes citaram uma melhora no entrosamento com outros profissionais e no relacionamento entre sua equipe, além de ter contribuído para o bom andamento de sua gestão. Além disso, parcerias entre os Cecanes e o poder público tendem a fortalecer cada vez mais as gestões nos municípios, para que se obtenha sucesso no que diz respeito aos trabalhos e compras feitos pelo PNAE (ALEXANDRE et al., 2016).

Diante disso, a constante atualização e formação dos nutricionistas atuantes no PNAE tem se tornado de grande importância, levando em conta as diversas atividades que o nutricionista realiza no Programa, principalmente no que diz respeito à aquisição dos gêneros alimentícios e formação de bons hábitos nos alunos (CHAVES et al., 2013), tornando-se imprescindível a busca de conhecimentos e troca de ideias com outros profissionais, para que, desta forma, obtenha-se um trabalho em equipe multidisciplinar.

A partir dos relatos das nutricionistas, no entanto, também são observadas algumas dificuldades relacionadas à aquisição de alimentos dos agricultores. No início da aprovação do artigo 14 da Lei $n^{\circ} 11.947 / 2009$ nesses municípios, muitos agricultores que fornecem alimentos para a alimentação escolar encontraram maiores dificuldades relativas à organização produtiva, à burocracia que envolve todo o processo de compra e venda dos alimentos e, também, à construção de agroindústrias, como relatado nos trechos das entrevistas:

Acho que fazer o pessoal entender né, e assim se adequar (...). Porque é fácil as pessoas chegarem e dizer: "Ah, eu tenho alface para vender", mas assim eu pego daqui e levo lá, sem documentação e isso a gente não pode aceitar. Mas no início foi bem complicadinho, justamente por causa da burocracia (N5).

[...] porque é muito mais fácil fazer uma licitação e pegar direto do mercado tudo. Porque assim, o transtorno é maior, tem um trabalho que envolve muita gente para a agricultura familiar [...] (N1).

Dificuldades teve no início né, primeiro a prática deles abrir uma agroindústria, toda essa parte burocrática, alguma coisa de transporte, a parte técnica para o agricultor abrir uma agroindústria (...) (N3).

Além disso, inicialmente os agricultores produziam pouca diversidade de alimentos e não tinham conhecimento de quantidade, o que ocasionava desperdício da produção. Autores descrevem, da mesma forma, a desorganização dos agricultores como um ponto desfavorável, levando em conta que nem sempre eles têm uma diversidade nos produtos, produzindo grande quantidade de um produto em específico e pouco ou quase nada de outros (ALEXANDRE et al., 2016; TRICHES; SCHNEIDER, 2012). Turpin (2009) ainda destaca, como dificuldade, a falta de profissionalização, de especificações sanitárias e de selos de inspeção necessários para a comercialização dos produtos. 
Segundo as nutricionistas, as questões higiênico-sanitárias também são uma barreira muito comum nos seus municípios, pois nem todos os produtos/agricultores atendem às especificações que são exigidas pela Lei. Estudos prévios (ALEXANDRE et al., 2016; TRICHES; SCHNEIDER, 2010a) também encontraram barreiras relacionadas à inspeção sanitária para a compra da agricultura familiar para Alimentação Escolar. Além disso, nem todos os municípios possuem o Serviço de Inspeção Municipal (SIM) ativo, dificultando ainda mais o controle e o suporte para os agricultores, principalmente no que diz respeito à produção de produtos de origem animal.

Cabe destacar, no entanto, que a dificuldade de regulamentação em relação aos aspectos higiênico-sanitários também é decorrente das altas exigências da legislação vigente para a produção em escala familiar, o que leva à exclusão de muitos agricultores dos mercados formais e institucionais (GAZOLLA, 2014; TRICHES; SCHNEIDER, 2010a). De acordo com Sousa et al. (2015), essas normas são elaboradas em consonância com o sistema alimentar convencional que privilegia a escala industrial e, dessa forma, tende a ser um limitante para os agricultores familiares.

Concordando com esses apontamentos, Marques et al. (2014) descrevem dificuldades relatadas por agricultores que criam barreiras para a agricultura familiar acessar mercados de forma regular e permanente. De acordo com os autores, essas dificuldades associam-se à estrutura física inadequada (dificultando, assim, a produção dos gêneros alimentícios), precariedade no transporte e atraso dos pagamentos. No presente estudo as questões de pagamentos não foram citadas.

Entre os municípios visitados, o apoio e parceria com outras entidades foi o ponto de maior destaque, pois, quando analisados os percentuais de compra da agricultura familiar, percebeu-se que os municípios desta pesquisa que possuem percentuais relevantes de compras chegando a $98 \%$, foram justamente os que trabalham com parcerias, como as Cooperativas de agricultores, apoio da Emater e das Secretarias de Agricultura, por exemplo. Bezerra et al. (2013) descrevem que a união entre diversos setores possibilitou uma melhora significativa na organização dos agricultores com relação à produção e comercialização dos seus produtos para a Alimentação Escolar.

No presente estudo verificou-se que nos municípios com maiores percentuais de compra da agricultura familiar existia um diálogo entre a nutricionista e os outros profissionais, chegando até o agricultor familiar. Nos demais municípios, em que cada setor trabalhava individualmente, o profissional realiza sua função sem haver troca de ideias ou informações, como indicam os trechos das entrevistas a seguir.

[...] nessa questão da Cooperativa, de ajudar, de incentivar os agricultores; a Emater trabalhou muito [...] eu falo que nós só temos a agricultura familiar tão forte aqui graças a ela e o trabalho da Cooperativa e nós aqui da Secretaria da Educação [secretária, nutricionista] todos que trabalharam juntos. É bem unido, todos se ajudam, o pessoal é muito legal de trabalhar, as pessoas são muito comprometidas (N3).

Em princípio foi a falta de organização assim da produção, da quantidade necessária né. E através da Cooper eles foram se adequando, a Emater também ajudou, [o mais foi a Cooper]. Fizemos várias reuniões com a Emater. A gente pergunta o que eles têm e faz o cardápio (N4). 
Nessa perspectiva, destaca-se a importância da intersetorialidade das ações e políticas públicas nos municípios. Sendo assim, é fundamental que haja a articulação e o engajamento entre os setores da educação, agricultura, saúde e administrativo na execução do Programa, que tem como público-alvo os escolares, mas por meio do fornecimento de alimentos saudáveis e adequados, contribui para a promoção da saúde e incentiva a produção de alimentos pela agricultura familiar (KROTH; GEREMIA; MUSSIO, 2020).

É importante enfatizar que, além desta política pública proporcionar aos alunos alimentação de qualidade, contribuindo para a melhoria dos hábitos alimentares e do desempenho escolar, ela atinge, de forma indireta, a geração de emprego e renda, o que fortalece a economia local do município.

\section{CONSIDERAÇÕES FINAIS}

Este estudo analisou a percepção das nutricionistas sobre aquisição de alimentos da agricultura familiar para a alimentação escolar no Território de Cidadania Noroeste Colonial - RS. Constatou-se, de acordo com os relatos das nutricionistas, que a compra desses produtos contribui diretamente para a geração de emprego e renda, incentivando os agricultores familiares desta região, além de proporcionar aos alunos uma alimentação mais saudável e de melhor qualidade, pois os alimentos, na forma in natura, são os que prevalecem nas listas de compras. Nesse contexto, entende-se, também, que a participação dos profissionais nutricionistas é relevante para a execução do Programa, principalmente pela sua atuação ampla e multidisciplinar.

As questões burocráticas, a falta de organização da produção por parte dos produtores e as questões sanitárias, no entanto, foram as principais dificuldades encontradas no início do processo de compra e venda dos alimentos do PNAE. Nesse sentido, é importante avançar em questões que envolvam orientações e incentivos para os produtores, além da adequação da legislação sanitária para a produção em pequena escala.

A atuação intersetorial por parte dos gestores, incluindo os agricultores, é de extrema importância para o sucesso final do processo que envolve o PNAE, posto que as capacitações recebidas pelas nutricionistas e a busca constante de conhecimento levam a uma melhora na organização e gestão da Alimentação Escolar.

Há, contudo, necessidade de ampliar o acesso ao PNAE nos municípios do Território da Cidadania Noroeste Colonial, com a criação de novas cooperativas de incentivo à produção e de suporte aos agricultores familiares, possibilitando um melhor entendimento por parte deles no que diz respeito às questões formais.

\section{REFERÊNCIAS}

ALEXANDRE, V. P. et al. Do campo à escola: compra de alimentos da agricultura familiar pelo Programa Nacional de Alimentação Escolar em Territórios da Cidadania de Goiás. Segurança Alimentar e Nutricional, v. 23, p. 1.049-1.064, 2016.

BACCARIN, J. G. et al. Alimentação escolar e agricultura familiar: alcance e dificuldades para implantação do artigo 14 da Lei 11.947/2009 no Estado de São Paulo. In: CONGRESSO DA SOCIEDADE BRASILEIRA DE ECONOMIA, ADMINISTRAÇÃO E SOCIOLOGIA RURAL, 49., 2011. Anais [...]. 2011. p. 1-20.

BALESTRIN, E. L B. As estratégias de inserção dos agricultores familiares no Programa de Alimentação Escolar de Capitão Leônidas Marques. 2014. Dissertação (Mestrado em Desenvolvimento Regional) - Universidade Tecnológica Federal do Paraná, Pato Branco, PR, 2014. 
BARDIN, L. Análise de conteúdo. São Paulo, SP: Edições, 2011. V. 70.

BELIK, W.; CHAIM, N. A. O programa nacional de alimentação escolar e a gestão municipal: eficiência administrativa, controle social e desenvolvimento local. Revista de Nutrição, v. 22, n. 5, p. 595-607, 2009. BEZERRA, O. M. P. A. et al. Promoção da aquisição de produtos da agricultura familiar para a alimentação escolar em Territórios da Cidadania de Minas Gerais e Espírito Santo. Revista de Nutrição, v. 26, n. 3, p. 335-342, 2013.

BRASIL. Lei no 11.947, de 16 de junho de 2009. Dispõe sobre o atendimento da alimentação escolar e do Programa Dinheiro Direto na Escola aos alunos da educação básica. Diário Oficial da União, 17 jun. 2009 b. BRASIL. Ministério de Educação e Cultura. Resolução FNDE/CD № 32, de 10 de agosto de 2006. Estabelecer as normas para a execução do Programa Nacional de Alimentação Escolar - PNAE. Diário Oficial da República Federativa do Brasil. Poder Executivo. Brasília, DF, agosto, 2006.

BRASIL. Ministério da Saúde. Secretaria de Atenção à Saúde. Coordenação-Geral de Alimentação e Nutrição. Guia alimentar para a população brasileira. Brasília, DF: Ministério da Saúde, 2014.

BRASIL. Programa de Aquisição de Alimentos da Agricultura Familiar. Brasília, DF, nov. 2012.

BRASIL. Série Desenvolvimento rural sustentável. Políticas públicas, atores sociais e desenvolvimento territorial no Brasil. Brasília, DF, ago. 2011.

BRASIL. Conselho Federal de Nutricionistas. Resolução/CFN no 465 de 23 de agosto de 2010. Dispõe sobre as atribuições do Nutricionista, estabelece parâmetros numéricos mínimos de referência no âmbito do Programa de Alimentação Escolar (PAE) e dá outras providências. Diário Oficial da União, 2010.

BRASIL. Territórios da cidadania noroeste colonial. Brasília, DF, maio, 2013.

BRASIL. Territórios da cidadania. Integração de Políticas Públicas para Reduzir Desigualdades. Brasília, DF, mar. 2009a.

CANIELLO, M. Identidade e qualidade de vida nos territórios da cidadania. Sociologias, v. 18, n. 43, p. 300334, dez. 2016.

CHAVES, L. G. et al. Reflexões sobre a atuação do nutricionista no Programa Nacional de Alimentação Escolar no Brasil. Ciência \& Saúde Coletiva, v. 18, p. 917-926, 2013.

FERIGOLLO, D. et al. Aquisição de produtos da agricultura familiar para alimentação escolar em municípios do Rio Grande do Sul. Revista de Saúde Pública, v. 51, p. 6, 2017.

FNDE. Fundo Nacional de Desenvolvimento da Educação. Alimentação escolar, repasses financeiros [Internet]. 2017. Disponível em: http://www.fnde.gov.br/index.php/programas/pnae/pnae-consultas/pnae-dados-da-agricultura-familiar. Acesso em: 7 jun. 2017.

GAZOLLA, M. Segurança alimentar e nutricional e agroindústrias familiares: políticas públicas e ações locais. Segurança Alimentar e Nutricional, v. 21, n. 2, p. 527-540, 2014.

GERMANO, A. M.; BUENO, M. C.; KIRSTEN, V. R. Alimentação escolar e agricultura familiar em municípios do litoral do Rio Grande do Sul: uma análise a partir da percepção das nutricionistas. Revista IDeAS, Rio de Janeiro, v. 14, p. 1-16, e020005, jan./dez. 2020.

GRISA, C.; SCHNEIDER, S. Três gerações de políticas públicas para a agricultura familiar e formas de interação entre sociedade e Estado no Brasil. Revista de Economia e Sociologia Rural, v. 52, p. 125-146, 2014. KROTH, D. C.; GEREMIA, D. S.; MUSSIO, B. R. Programa Nacional de Alimentação Escolar: uma política pública saudável. Ciência \& Saúde Coletiva, v. 25, p. 4.065-4.076, 2020.

MARQUES, A. A. et al. Reflexões de agricultores familiares sobre a dinâmica de fornecimento de seus produtos para a alimentação escolar: o caso de Araripe, Ceará. Saúde e Sociedade, v. 23, p. 1.329-1.341, 2014.

MINAYO, M. C. S. Construção dos instrumentos e exploração de campo. O desafio do conhecimento: pesquisa qualitativa em saúde. São Paulo: Hucitec, 2010. p. 189-99.

PEIXINHO, A. M. Lima. A trajetória do Programa Nacional de Alimentação Escolar no período de 20032010: relato do gestor nacional. Ciência \& Saúde Coletiva, v. 18, p. 909-916, 2013.

SANTANA, T. C. M.; MORENO, L. R. Formação do nutricionista atuante no Programa Nacional de Alimentação Escolar. Nutrire Rev. Soc. Bras. Aliment. Nutr., v. 37, n. 2, p. 183-198, 2012.

SARAIVA, E. B. et al. Panorama da compra de alimentos da agricultura familiar para o Programa Nacional de Alimentação Escolar. Ciência \& Saúde Coletiva, v. 18, p. 927-935, 2013.

SCARPARO, A. L. S. et al. Ações do centro colaborador em alimentação e nutrição do escolar da Universidade Federal do Rio Grande do Sul. Clinical \& Biomedical Research, v. 30, n. 3, 2010.

SCARPARO, A. L. S. et al. Formação para nutricionistas que atuam no Programa Nacional de Alimentação Escolar: uma avaliação da efetividade. Ciência \& Saúde Coletiva, v. 18, p. 1.001-1.008, 2013. 
SIT. Sistema de Informações Territoriais. Caderno Territorial 147 Noroeste Colonial - RS. 2015. Disponível em: http://sit.mda.gov.br/download/caderno/caderno_territorial_147_Noroeste\%20Colonial\%20-\%20RS.pdf. Acesso em: 22 abr. 2021.

SOUSA, A. A. et al. Cardápios e sustentabilidade: ensaio sobre as diretrizes do Programa Nacional de Alimentação Escolar. Revista de Nutrição, p. 217-229, 2015.

TRICHES, R. M.; SCHNEIDER, S. Alimentação escolar e agricultura familiar: reconectando o consumo à produção. Saúde e Sociedade, v. 19, p. 933-945, 2010 a.

TRICHES, R. M.; SCHNEIDER, S. Desestruturar para construir: interfaces para a agricultura familiar acessar o programa de alimentação escolar. Estudos Sociedade e Agricultura, Rio de Janeiro, v. 20, n. 1, p. 66-105, 2012.

TRICHES, R. M.; SCHNEIDER, S. Reconstruindo o "elo perdido": a reconexão da produção e do consumo de alimentos através do Programa de Alimentação Escolar no município de Dois Irmãos (RS). Segurança Alimentar e Nutricional, v. 17, n. 1, p. 1-15, 2010 b.

TURPIN, M. E. A alimentação escolar como fator de desenvolvimento local por meio do apoio aos agricultores familiares. Segurança Alimentar e Nutricional, v. 16, n. 2, p. 20-42, 2009. 